\title{
A More Natural Way of Seeing: Visual Performance of Three Presbyopia Correcting Intraocular Lenses
}

\author{
Amir Hamid, Arif Sokwala \\ Optimax and Ultralase Clinics, London, UK \\ Email: info@dramirhamid.com
}

Received 20 July 2016; accepted 19 August 2016; published 22 August 2016

Copyright (C 2016 by authors and Scientific Research Publishing Inc.

This work is licensed under the Creative Commons Attribution International License (CC BY). http://creativecommons.org/licenses/by/4.0/

(c) (i) Open Access

\section{Abstract}

Purpose: To compare the visual and refractive outcomes, patient satisfaction and spectacle independence between three novel designs of diffractive IOLs. Method: Prospective study including 150 patients with implantation of three IOLs: trifocal diffractive IOL AT LISA tri 839 MP (ATLISA, $n$ $=50$ ), trifocal diffractive IOL PhysIOL FineVision (FineVision, $\mathbf{n}=50$ ) and the extended range of vision IOL Tecnis Symfony ZRX00 (Symfony, $n=50$ ). Patients were followed up for 6 months after surgery. Major parameters were monocular and binocular uncorrected (UDVA) and corrected (CDVA) distance, uncorrected (UIVA) and distance corrected (DCIVA) intermediate $(80 \mathrm{~cm})$, and uncorrected (UNVA) and distance corrected (DCNVA) near $(40 \mathrm{~cm})$ visual acuities (UNVA), contrast sensitivity (CS), defocus curve as well as patient satisfaction and spectacle use. Results: Mean postoperative decimal UDVA was 1.01 for Symfony, 0.96 for ATLISA and 0.95 for the FineVision IOL. Postoperative UIVA was 0.95 with Symfony, 0.72 with ATLISA and 0.85 with the FineVision IOL. Postoperative UNVA was 0.96 with the FineVision, 0.72 with the ATLISA and 0.63 with the Symfony IOL. The Symfony defocus curve showed the smoothest profile. Mean mesopic CS was 0.84 $\log$ units with the Symfony, 0.83 with the ATLISA (0.83) and 0.65 with the FineVision IOL. Mean photopic CS with the Symfony, ATLISA and FineVision was 1.05, 0.85 and 0.69 log units, respectively. Twenty percent of the patients with the ATLISA and FineVision IOLs and $5.6 \%$ of the Symfony patients reported halos and glare as troublesome or disabling. Reading glasses were frequently used by $5.6 \%$ of the Symfony patients. All patients with the trifocal IOLs reported to be spectacle-free for any distance. Conclusion: All 3 IOLs produce excellent results with high levels of spectacle independence. The Symfony produces better levels of distance and intermediate visual acuity, whereas the trifocal IOLs produced better near vision. Higher frequency of dysphotopsia was seen with the trifocal IOLs. 


\section{Keywords}

\section{Extended Range of Vision, Tecnis Symfony, Trifocal, Defocus Curve, Visual Outcome}

\section{Introduction}

Cataract surgery has evolved from a simple procedure of removing the opacified crystalline lens to a method that additionally aims to correct all refractive errors. In the past years, the major goal of the implantation of intraocular lenses (IOLs) was the achievement of emmetropia for distance. Currently, IOLs are able to compensate not only for spherical errors, but also for astigmatism and presbyopia, providing a complete restoration of the visual function with high levels of spectacle independence. Multifocal intraocular lenses (MIOLs) are designed to reduce spectacle dependence improving certain aspects related to quality of life. To date, there is scientific evidence of the significant improvement of uncorrected near visual acuity (UNVA) after the implantation of MIOLs compared to monofocal IOLs, without a significant decrease of uncorrected distance visual acuity (UDVA) [1]. However, there are some concerns regarding the visual quality provided by MIOLs, such as glare, halos or reduced contrast sensitivity (CS).

Earlier MIOL designs were bifocal, allowing the patient to obtain a postoperative functional distance and near visual acuity. Nowadays, the extended usage of computers and mobile devices has changed the preference of spectacle independence from near to intermediate distances. The latest generation of MIOLs based on diffractive platforms is able to distribute light in more than two different foci, the trifocal IOLs [2]-[4]. These three focal points can be generated in two ways, either by combining two bifocal diffractive profiles in one surface of the IOL [3] or by using a trifocal diffractive profile combined with a bifocal diffractive optic [2] [5]. Besides MIOLs, other new concepts have been developed on the basis of a diffractive optic pattern, such as the extended range of vision IOL Tecnis Symfony. We have recently conducted a study to compare the visual and refractive outcomes as well as patient satisfaction and spectacle independence between three novel designs of diffractive IOLs.

\section{Patients and Methods}

We conducted a prospective clinical study including 150 patients undergoing cataract surgery or clear lens extraction with implantation of three different IOLs: the trifocal diffractive IOL ATLISA tri 839MP (50 patients), the trifocal diffractive IOL PhysIOL FineVision (50 patients) and the extended range of vision IOL Tecnis Symfony ZRX00 (50 patients). The preoperative refractive and demographic characteristics of the evaluated sample are summarized in Table 1. Exclusion criteria comprised previous ocular surgery including corneal or refractive surgery, chronic or recurrent uveitis, acute ocular disease or external/internal infection, diabetes with retinal changes, glaucoma or intraocular pressure (IOP) equal or higher than $24 \mathrm{mmHg}$, pseudoexfoliation syndrome, pathological miosis, keratoconus, and corneal endothelial dystrophy. All patients were informed about the study and provided informed consent to undergo the clinical examinations in accordance with the tenets of the Declaration of Helsinki. The study was approved by an institutional review board.

Before surgery, all patients underwent a comprehensive preoperative ophthalmological examination that included measurement of monocular and binocular uncorrected distance (UDVA), intermediate (80 cm) (UIVA), and near $(40 \mathrm{~cm})$ visual acuity (UNVA), monocular and binocular corrected distance (CDVA), distance-corrected intermediate (DCIVA) and distance-corrected near visual acuity (DCNVA), optical biometry (IOL Master, Carl Zeiss Meditec AG, Germany), manifest refraction, biomicroscopy, Goldmann applanation tonometry, and dilated fundoscopy. Patients were evaluated at 1 week and at 2, 3 and 6 months after surgery. Visual acuities, subjective refraction, contrast sensitivity function under mesopic and photopic conditions with the Thomson Charts (http://www.thomson-software-solutions.com/test-chart-xpert-3di/) and the defocus curve were assessed at each visit. In addition, at the end of the follow-up, patients were asked about the perception of photic phenomena or visual disturbances, such as glare or halos, as well as about their need for using spectacles for reading or intermediate distance. Specifically, the questionnaire consisted of various items that scored the perception of glare and halos. Each item was scored from none (minimum) to disabling (maximum). The overall satisfaction was scored on the basis of 3 items: choice of same multifocal IOL again, recommendation to friends and family, and the use of spectacles at far, near and intermediate distances. 
Table 1. Preoperative refractive and demographic characteristics of patients implanted with each type of IOL. Abbreviations: M (male), F (female), SD (standard deviation), Pre-op (preoperative), SEQ (spherical equivalent), Cyl (cylinder), Post-op (postoperative), D (diopters).

\begin{tabular}{cccc}
\hline & Tecnis Symfony ZXR00 & AT LISA tri & FineVision \\
\hline Males/Females & $1: 2$ & $1: 2$ & $1: 2$ \\
Mean Age (SD) & $57.8 \pm 6.03$ & $56.9 \pm 7.01$ & $58.2 \pm 9.41$ \\
Age Range & $34-74$ & $39-73$ & $50-75$ \\
Pre-op SEQ & $0.6 \pm 1.19$ & $0.2 \pm 1.36$ & $-0.05 \pm 0.78$ \\
Pre-op Sphere Range & -1.25 to $4.75 \mathrm{D}$ & -3.75 to $4.25 \mathrm{D}$ & -6.25 to $0.25 \mathrm{D}$ \\
Pre-op Cyl Range & -1.25 to $0 \mathrm{D}$ & -1.5 to $0 \mathrm{D}$ & -0.50 to $0 \mathrm{D}$ \\
Post-op SEQ & $-0.1 \pm 0.23$ & $0.0 \pm 0.19$ & $0.0 \pm 0.10$ \\
\hline
\end{tabular}

Statistical analysis was performed with the SPSS statistics software package version 15.0.1 for Windows (IBM, Armonk, NY, USA). Normality of data distribution was analysed with the Kolmogorov-Smirnov test. When parametric analysis was possible, the Student $t$ test for paired data was used for all parameter comparisons between preoperative and postoperative examinations as well as between consecutive postoperative visits. Otherwise, when parametric analysis was not possible, the Wilcoxon Rank Sum test was applied to assess the significance of differences between consecutive examinations. In all cases, the same level of significance $(\mathrm{p}<0.05)$ was considered.

\section{Results}

\subsection{Visual Outcomes}

The Tecnis Symfony IOL provided the best results for distance visual acuity. Mean postoperative UDVA was 1.01 (decimal scale), and CDVA changed from 1.08 preoperatively to 1.09 postoperatively. Likewise, the AT LISA tri IOL also provided good distance visual results, with a mean postoperative UDVA of 0.96 and a CDVA not changing significantly with surgery from 1.04 to 1.03. In contrast, the FineVision IOL showed the lowest mean postoperative value of UDVA (0.95), but with a significant increase in CDVA (from 1.05 to 1.10). The differences in UDVA between Tecnis Symfony and ATLISA tri $(\mathrm{p}=0.048)$ as well as Tecnis Symfony and FineVision $(\mathrm{p}=0.006)$ were statistically significant.

Regarding intermediate distance, the Symfony IOL was again the best option. With this IOL, a postoperative UIVA of 0.95 was achieved while mean values of 0.72 and 0.85 were obtained with the ATLISA and FineVision IOLs, respectively. The differences between the Symfony IOL and the other two lens models were statistically significant ( $p=0.0018$ vs AT LISA; $p=0.021$ vs FineVision).

In our sample, a mean UNVA of 0.96 was obtained with the FineVision IOL while a mean value of 0.72 was obtained with the AT LISA tri IOL. A statistically significant difference was observed when these trifocal IOLs were compared with the Symfony IOL ( $0.63 ; p=0.03$ vs AT LISA; $p=0.033$ vs FineVision) (Figure 1 ).

\subsection{Defocus Curve}

The Symfony IOL provided the smoother profile along the whole defocus curve, with a more progressive visual acuity decrease to the higher levels of defocus, while both diffractive trifocal IOL models showed some distinct peaks based on their optic designs. Specifically, the Symfony IOL was clearly superior to the trifocal IOLs at defocus levels of $-1 \mathrm{D}$ and $-1.50 \mathrm{D}$ that correspond with the vergence demands required for intermediate distance (Figure 2).

\subsection{Contrast Sensitivity Outcomes}

A mean mesopic CS of $0.84 \log$ units was achieved with the Symfony IOL, a significantly higher level than that obtained with the AT LISA IOL $(0.83 ; p=0.017)$ and the FineVision trifocal IOL $(0.65 ; p=0.02)$. Under 


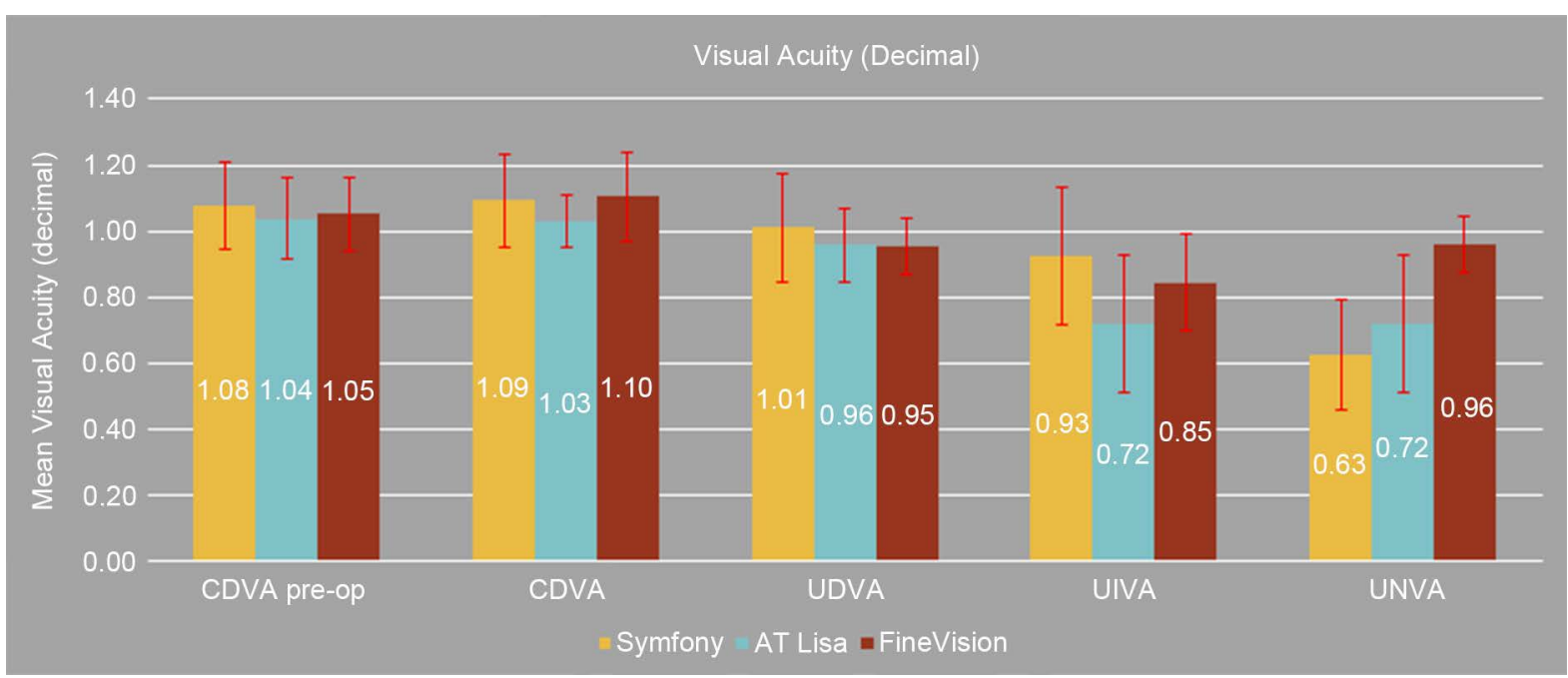

Figure 1. Mean postoperative visual acuities in the three IOL subgroups. Abbreviations: Preop (preoperative); CDVA (corrected distance visual acuity); UDVA (uncorrected distance visual acuity); UIVA (uncorrected intermediate visual acuity); UNVA (uncorrected near visual acuity); DCNVA (distance corrected near visual acuity).

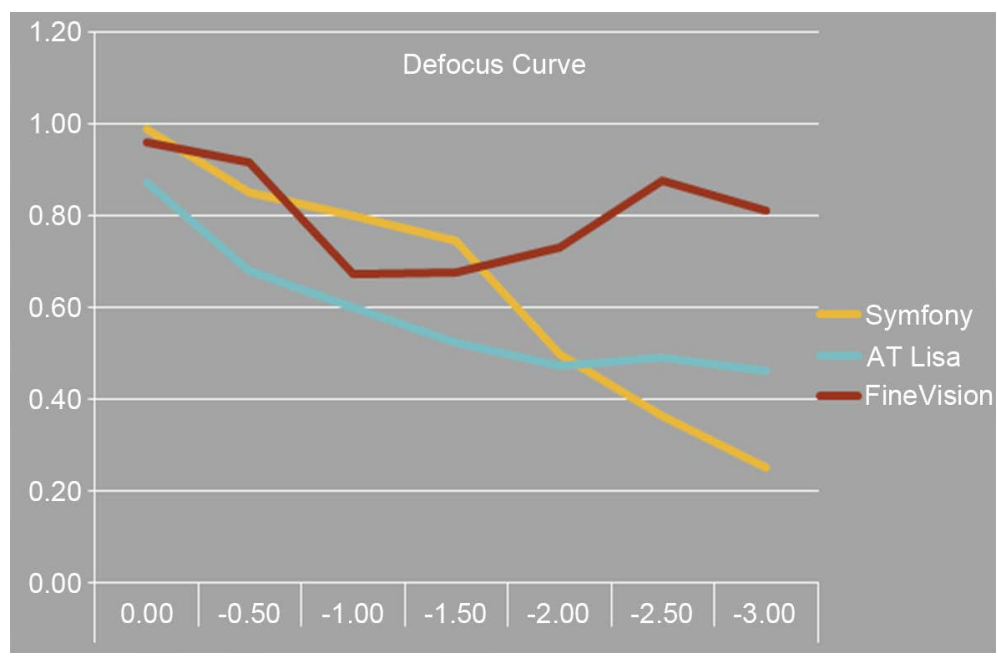

Figure 2. Defocus curves for different defocus levels from 0 to $-3 \mathrm{D}$ in the three IOL subgroups.

photopic conditions, the Symfony IOL provided significantly higher levels of CS (1.05 log units), with clearly inferior CS values for the Fine Vision and AT LISA tri IOLs (0.69 log units; $\mathrm{p}=0.03$ and $0.85 \log$ units; $\mathrm{p}=$ 0.02 ) respectively) (Figure 3 ).

\subsection{Photic Phenomena and Patient Satisfaction}

In our series, $20 \%$ of patients with the AT LISA and FineVision IOLs reported each, halos and glare as troublesome or even disabling (Figure 4). Only 5.6\% of the patients with the extended range of vision IOL, Symfony, rated halos and glare as troublesome and none of the patients felt disabled by these photic phenomena.

A total of $94.4 \%$ of patients implanted with the Symfony IOL would choose the same IOL again and would recommend this IOL model to their friends and family. Likewise, a patient satisfaction rate of $93.3 \%$ was obtained with the ATLISA IOL, whereas a dissatisfaction rate of $20 \%$ was obtained with the FineVision IOL. Almost $95 \%$ of patients did not need spectacles at any distance after the implantation of the Symfony IOL. Only 5.6\% needed reading glasses frequently (Figure 5). All patients with the trifocal IOLs reported that they did not need spectacles for any distance. 


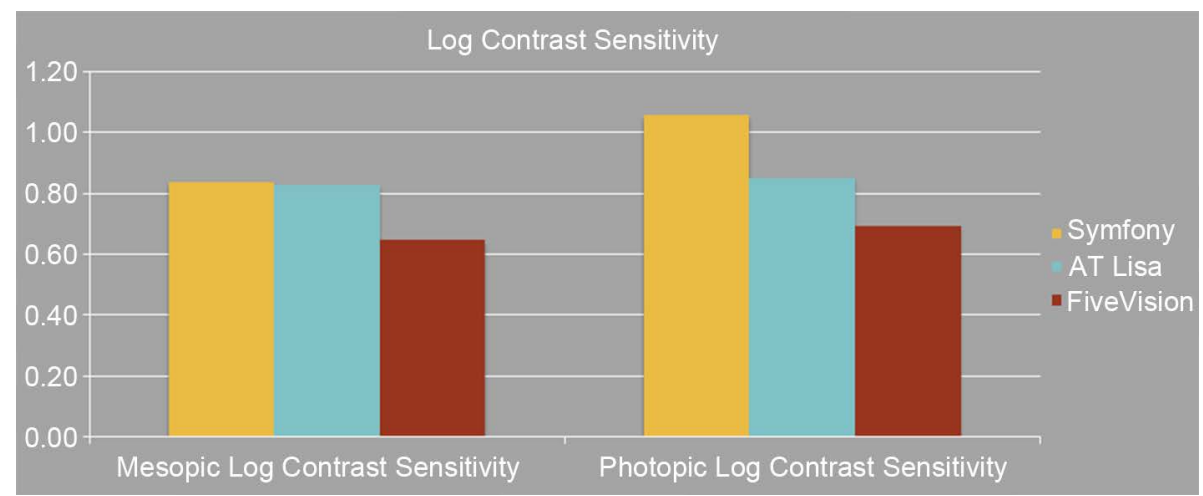

Figure 3. Contrast sensitivity values under photopic and mesopic conditions in the three IOL subgroups.

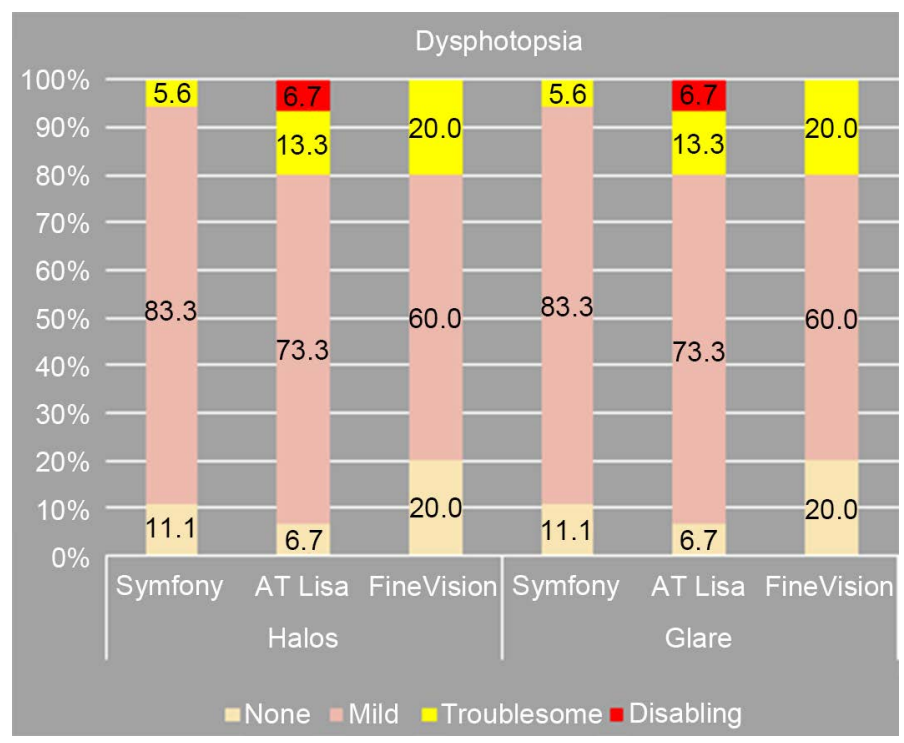

Figure 4. Rates of photic phenomena (halos and glare) in the three IOL subgroups.

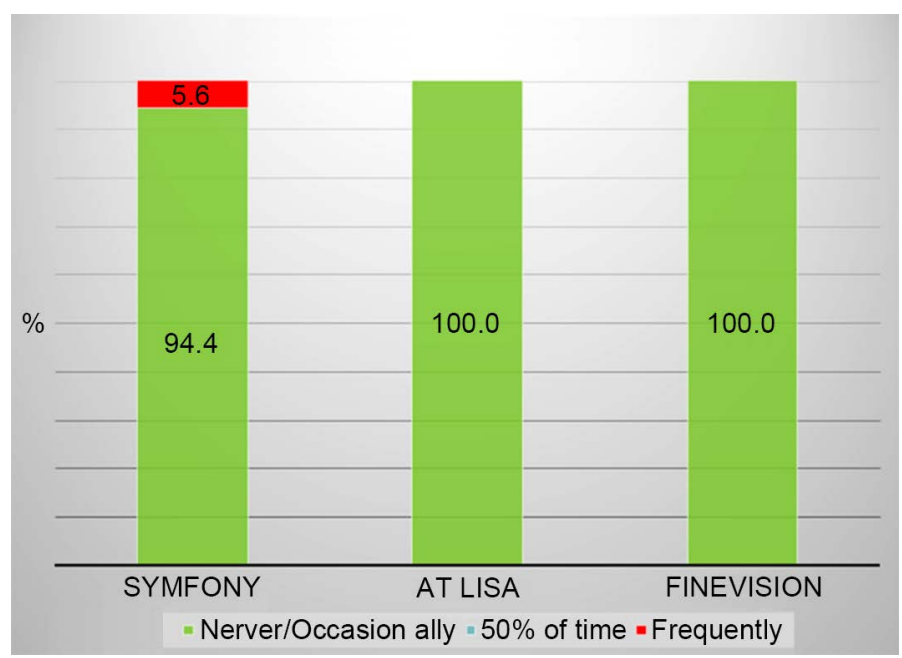

Figure 5. Spectacle independence rates for near vision in the three IOL subgroups. 


\section{Discussion}

The Tecnis Symfony IOL is a new promising alternative to provide an extended effective and continuous range of optimum vision from far to near distances after cataract surgery or refractive lens exchange. This IOL is based on a new echelette optic design and combines the compensation for chromatic aberration and primary spherical aberration [6] [7]. Although there is still a lack of clinical studies reporting the clinical outcomes of this IOL, in-vitro studies have shown its ability to provide an enlarged depth of focus [8]. Likewise, experimental studies have revealed that the modulation transfer function (MTF) of the Tecnis Symfony IOL for intermediate distances is comparable to that achieved with trifocal IOLs [9]. This is consistent with the results obtained in our study.

Distance visual outcomes were excellent with all studied IOLs. This confirms the ability of the lenses to successfully restore the distance visual function, as also shown for different models of multifocal IOLs [5] [10]-[25]. A mean monocular UDVA of $0.05 \pm 0.07$ logMAR (decimal 0.89) was reported by Law et al. [14] in patients bilaterally implanted with the ATLISA trifocal IOL. Kohnen et al. [24] found a mean binocular UDVA of -0.06 $\pm 0.10 \operatorname{logMAR}$ (decimal 1.16) after implantation of the same lens model. With the FineVision IOL, mean monocular 2-month and 6-month postoperative logMAR UDVA values of $0.19 \pm 0.09$ (decimal 0.65) and $0.18 \pm$ 0.13 (decimal 0.66) were reported by Sheppard et al. [18] and Alió et al. [17], respectively. Jonker et al found binocular UDVA values of $0.01 \pm 0.11$ (decimal 0.98) logMAR after bilateral implantation of the FineVision IOL [25].

The Symfony IOL showed the best UIVA values in our study with 0.95 , compared to 0.72 and 0.85 for the ATLISA and FineVision IOLs, respectively. Mean logMAR UIVA values of $0.08 \pm 0.10$ (decimal 0.83; measured at $66 \mathrm{~cm}$ ) and $0.03 \pm 0.08$ (decimal 0.93; measured at $80 \mathrm{~cm}$ ) have been reported by Mojzis et al. in two case series with the ATLISA trifocal IOL [5] [15]. Kohnen et al. [24] found binocular UIVA values of $0.00 \pm$ 0.12 (decimal 1.0) with this lens model.Two separate studies reported mean logMAR UIVA values of $0.08 \pm$ 0.12 (decimal 0.83; measured at $65 \mathrm{~cm}$ ) [13] and $0.05 \pm 0.19$ (decimal 0.89; measured at $70 \mathrm{~cm}$ ) [19]. Mean UIVA values of $0.20 \pm 0.11 \log M A R$ (decimal 0.63 ; measured at $80 \mathrm{~cm}$ ) and $0.32 \pm 0.15 \log$ MAR (decimal 0.48; measured at $70 \mathrm{~cm}$ )were obtained in two studies evaluating the same type of trifocal IOL [17] [25].

As expected, near visual acuity outcomes improved with increasing near addition of the IOL, with the FineVision IOL showing the best results, followed by ATLISA and Symfony. Law et al. [1] reported a mean binocular UNVA value of $0.16 \pm 0.07 \operatorname{logRAD}$ (decimal 0.69 ; measured at $40 \mathrm{~cm}$ ) in a group of eyes implanted with the ATLISA trifocal IOL, Kohnen et al. [24] reported bilateral UNVA values of $0.04 \pm 0.10$ (decimal 0.91) and Mojzis [5] found a monocular mean UNVA of $0.20 \pm 0.12 \operatorname{logMAR}$ (decimal 0.63; measured at $33 \mathrm{~cm}$ ) with the same lens model. With the FineVision trifocal IOL, Alió et al. [17] reported a mean monocular UNVA of $0.26 \pm 0.15$ (decimal 0.55; measured at $40 \mathrm{~cm}$ ) and Jonker et al. [25] $0.15 \pm 0.13$ logMAR (decimal 0.71). Mean $\operatorname{logMAR}$ UNVA values of $0.11 \pm 0.12$ (decimal 0.11 ; measured at $35 \mathrm{~cm}$ ) and $0.01 \pm 0.06$ (decimal 0.98; measured at $35 \mathrm{~cm}$ ) have been reported by Vryghem and Heireman [19] and Cochener et al. [13].

The perception of visual disturbances is a common occurence after the implantation of diffractive multifocal IOLs. Although the rate of severe symptoms is usually low, a significant percentage of patients may consider them as disabling, leading to dissatisfaction. Those symptoms usually decrease with time, probably as a result of a neuro-adaptive mechanism. In our series, patients with the Symfony IOL reported less troublesome photic phenomena than patients implanted with the trifocal lenses. None of the Symfony patients felt disabled by these symptoms. Law et al. [14] found that $80 \%$ of patients reported difficulties associated to halo perception at 1 month after implantation of the ATLISA trifocal IOL. This percentage decreased to $40 \%$ at 6 months after surgery [14]. In another study with the same lens model, the most common visual symptom was halos, which were reported by $60 \%$ of the patients, followed by glare in $28 \%$ and starburst in $8 \%$ of the patients [24]. In a retrospective study, Kamiya et al. [26] found that disabling photic phenomena were one of the main causes for multifocal IOL explantation. The optic lens design of the Symfony IOL with the elongated focus instead of distinct focal points might have contributed to the low level of photic phenomena.

In our sample, the Symfony IOL provided the best performance in terms of CS when compared with the trifocal IOLs. Under mesopic conditions, Symfony and ATLISA showed comparable results, whereas CS with the FineVision was significantly worse. Under photopic conditions Symfony was significantly better than both trifocal IOLs. Marques and Ferreira [27] reported no significant differences in contrast sensitivity between eyes with the FineVision and eyes with the ATLISA IOL. Law et al. [14] used the Pelli Robson test to measure CS in 
patients with the ATLISA IOL and found no differences between mesopic and photopic results. Also, the light distribution of the Symfony IOL between its best vision foci has been demonstrated to be more homogeneous and less vergence dependent under dim conditions compared to multifocal IOLs [28].

The defocus curve of the Symfony IOL showed the smoothest profile. and was superior to the trifocal IOLs at defocus levels of $-1 \mathrm{D}$ and $-1.50 \mathrm{D}$ which are important for intermediate vision. In another study by Mojzis et $a l$. [5] the defocus curve of the ATLISA trifocal IOL showed a maximum of visual acuity at a defocus of zero and a slight drop with increasing defocus but a functional range of visual acuity with values of 0.1 logMAR or better at defocus levels between $0 \mathrm{D}$ and $2.5 \mathrm{D}$.

None of the patients with trifocal IOLs in our series reported to need glasses for any distance. Despite the lower near addition, only $5.6 \%$ of the Symfony patients needed reading glasses frequently. Kohnen et al. [24] found in his study with the ATLISA trifocal IOL that $100 \%$ of the patients were independent of spectacles for distance and intermediate vision and 12\% needed occasional near correction. Law et al. [14] reported that a limited percentage of patients implanted with the same IOL had some difficulties to perform near and intermediate visual tasks without glasses, such as reading the newspaper or working with the computer [14]. In a study with the FineVision IOL, 80\% of the patients were reported to be completely spectacle independent [25].

Patient satisfaction was very high in our series with $94.4 \%$ of the Symfony patients and $93.3 \%$ of the ATLISA patients who would choose the same IOL again and would recommend this IOL model to their friends and family. The dissatisfaction rate was higher in the FineVision group with $20 \%$ of the patients reporting that they would not choose the same lens again or recommend the lens.

\section{Conclusion}

In summary, the Tecnis Symfony IOL, designed to restore visual function after extraction of the crystalline lens, provides excellent efficacy outcomes regarding visual acuity at far and intermediate distances. Only a very low percentage of patients need spectacles for near distances. The rate of halos and glare is significantly lower compared to the trifocal diffractive IOL models. Therefore, the combination of the good visual outcome based on the extended range of vision, the high spectacle independence and the low incidence of disabling photic phenomena lead to somewhat higher levels of patient satisfaction compared to the trifocal IOLs.

\section{References}

[1] Calladine, D., Evans, J.R., Shah, S. and Leyland, M. (2012) Multifocal versus Monofocal Intraocular Lenses after Cataract Extraction. Cochrane Database of Systematic Reviews, 12, CD003169.

[2] Voskresenskaya, A., Pozdeyeva, N., Pashtaev, N., Batkov, Y., Treushnicov, V. and Cherednik, V. (2010) Initial Results of Trifocal Diffractive IOL Implantation. Graefe's Archive for Clinical and Experimental Ophthalmology, 248, 1299-1306. http://dx.doi.org/10.1007/s00417-010-1424-8

[3] Gatinel, D., Pagnoulle, C., Houbrechts, Y. and Gobin, L. (2011) Design and Qualification of a Diffractive Trifocaloptical Profile for Intraocular Lenses. Journal of Cataract \& Refractive Surgery, 37, 2060-2067. http://dx.doi.org/10.1016/j.jcrs.2011.05.047

[4] Valle, P.J., Oti, J.E., Canales, V.F. and Cagigal, M.P. (2005) Visual Axial PSF of Diffractive Trifocal Lenses. Optics Express, 13, 2782-2792. http://dx.doi.org/10.1364/OPEX.13.002782

[5] Mojzis, P., Peña-García, P., Liehneova, I., Ziak, P. and Alió, J.L. (2014) Outcomes of a New Diffractive Trifocal Intraocular Lens. Journal of Cataract \& Refractive Surgery, 40, 60-69. http://dx.doi.org/10.1016/j.jcrs.2013.06.025

[6] Weeber, H.A. and Piers, P.A. (2012) Theoretical Performance of Intraocular Lenses Correctiong Both Spherical and Chromatic Aberration. Journal of Refractive Surgery, 28, 48-52. http://dx.doi.org/10.3928/1081597X-20111103-01

[7] Artal, P., Manzanera, S., Piers, P. and Weeber, H. (2010) Visual Effect of the Combined Correction of Spherical and Longitudinal Chromatic Aberrations. Optics Express, 18, 1637-1648. http://dx.doi.org/10.1364/OE.18.001637

[8] Domínguez-Vicent, A., Esteve-Taboada, J.J., Del Águila-Carrasco, A.J., Ferrer-Blasco, T. and Montés-Micó, R. (2015) In Vitro Optical Quality Comparison between the Mini WELL Ready Progressive Multifocal and the TECNIS Symfony. Graefe's Archive for Clinical and Experimental Ophthalmology.

[9] Gatinel, D. and Loicq, J. (2016) Clinically Relevant Optical Properties of Bifocal, Trifocal, and Extended Depth of Focus Intraocular Lenses. Journal of Refractive Surgery, 32, 273-280. http://dx.doi.org/10.3928/1081597X-20160121-07

[10] Kretz, F.T., Gerl, M., Gerl, R., Müller, M., Auffarth, G.U., ZKB00 Study Group (2015) Clinical Evaluation of a New Pupil Independent Diffractive Multifocal Intraocular Lens with a +2.75 D near Addition: A European Multicentre Stu- 
dy. British Journal of Ophthalmology. http://dx.doi.org/10.1136/bjophthalmol-2015-306811

[11] Cillino, G., Casuccio, A., Pasti, M., Bono, V., Mencucci, R. and Cillino, S. (2014) Working-Age Cataract Patients: Visual Results, Reading Performance, and Quality of Life with Three Diffractive Multifocal Intraocular Lenses. Ophthalmology, 121, 34-44. http://dx.doi.org/10.1016/j.ophtha.2013.06.034

[12] Lubiński, W., Gronkowska-Serafin, J. and Podborączyńska-Jodko, K. (2014) Clinical Outcomes after Cataract Surgery with Implantation of the Tecnis ZMB00 Multifocal Intraocular Lens. Medical Science Monitor, 20, 1220-1226. http://dx.doi.org/10.12659/MSM.890585

[13] Cochener, B., Vryghem, J., Rozot, P., Lesieur, G., Chevalier, J.P., Henry, J.M., David, T., Lesueur, L., Gatinel, D., Ganem, C., Blanckaert, J., Van Acker, E., Heireman, S. and Ghekiere, S. (2014) Clinical Outcomes with a Trifocal Intraocular Lens: A Multicenter Study. Journal of Refractive Surgery, 30, 762-768. http://dx.doi.org/10.3928/1081597X-20141021-08

[14] Law, E.M., Aggarwal, R.K. and Kasaby, H. (2014) Clinical Outcomes with a New Trifocal Intraocular Lens. European Journal of Ophthalmology, 24, 501-508. http://dx.doi.org/10.5301/ejo.5000407

[15] Mojzis, P., Kukuckova, L., Majerova, K., Liehneova, K. and Piñero, D.P. (2014) Comparative Analysis of the Visual Performance after Cataract Surgery with Implantation of a Bifocal or Trifocal Diffractive IOL. Journal of Refractive Surgery, 30, 666-672. http://dx.doi.org/10.3928/1081597X-20140903-06

[16] Schmickler, S., Bautista, C.P., Goes, F., Shah, S. and Wolffsohn, J.S. (2013) Clinical Evaluation of a Multifocal Aspheric Diffractive Intraocular Lens. British Journal of Ophthalmology, 97, 1560-1564. http://dx.doi.org/10.1136/bjophthalmol-2013-304010

[17] Alió, J.L., Montalbán, R., Peña-García, P., Soria, F.A. and Vega-Estrada, A. (2013) Visual Outcomes of a Trifocal Aspheric Diffractive Intraocular Lens with Microincision Cataract Surgery. Journal of Refractive Surgery, 29, 756-761. http://dx.doi.org/10.3928/1081597X-20131021-05

[18] Sheppard, A.L., Shah, S., Bhatt, U., Bhogal, G. and Wolffsohn, J.S. (2013) Visual Outcomes and Subjective Experience after Bilateral Implantation of a New Diffractive Trifocal Intraocular Lens. Journal of Cataract \& Refractive Surgery, 39, 343-349. http://dx.doi.org/10.1016/j.jcrs.2012.09.017

[19] Vryghem, J.C. and Heireman, S. (2013) Visual Performance after the Implantation of a New Trifocal Intraocular Lens. Clinical Ophthalmology, 7, 1957-1965. http://dx.doi.org/10.2147/OPTH.S44415

[20] Ramón, M.L., Piñero, D.P. and Pérez-Cambrodí, R.J. (2012) Correlation of Visual Performance with Quality of Life and Intraocular Aberrometric Profile in Patients Implanted with Rotationally Asymmetric Multifocal IOLs. Journal of Refractive Surgery, 28, 93-99. http://dx.doi.org/10.3928/1081597X-20111213-02

[21] Alió, J.L., Plaza-Puche, A.B., Piñero, D.P., Amparo, F., Jiménez, R., Rodríguez-Prats, J.L., Javaloy, J. and Pongo, V. (2011) Optical Analysis, Reading Performance, and Quality-of-Life Evaluation after Implantation of a Diffractive Multifocal Intraocular Lens. Journal of Cataract \& Refractive Surgery, 37, 27-37. http://dx.doi.org/10.1016/j.jcrs.2010.07.035

[22] Alió, J.L., Piñero, D.P., Plaza-Puche, A.B. and Rodriguez-Chan, M.J. (2011) Visual Outcomes and Optical Performance of a Monofocal Intraocular Lens and a New-Generation Multifocal Intraocular Lens. Journal of Cataract \& Refractive Surgery, 37, 241-250. http://dx.doi.org/10.1016/j.jcrs.2010.08.043

[23] Alfonso, J.F., Puchades, C., Fernández-Vega, L., Montés-Micó, R., Valcárcel, B. and Ferrer-Blasco, T. (2009) Visual Acuity Comparison of 2 Models of Bifocal Aspheric Intraocular Lenses. Journal of Cataract \& Refractive Surgery, 35, 672-676. http://dx.doi.org/10.1016/j.jcrs.2008.11.061

[24] Kohnen, T., Titke, C. and Böhm, M. (2015) Trifocal Intraocular Lens Implantation to Treat Visual Demands in Various Distances Following Lens Removal. American Journal of Ophthalmology, 161, 71-77.e1.

[25] Jonker, S.M.R., Bauer, N.J.C., Makhotkina, N.Y., Berendschot, T.T.J.M., van den Biggelaar, F.J.H.M. and Nuijts, R.M.M.A. (2015) Comparison of a Trifocal Intraocular Lens with a +3.0 D Bifocal IOL: Results of a Prospective Randomized Clinical Trial. Journal of Cataract \& Refractive Surgery, 41, 1631-1640. http://dx.doi.org/10.1016/j.jcrs.2015.08.011

[26] Kamiya, K., Hayashi, K., Shimizu, K., Negishi, K., Sato, M. and Bissen-Miyajima, H., Survey Working Group of the Japanese Society of Cataract and Refractive Surgery (2014) Multifocal Intraocular Lens Explantation: A Case Series of 50 Eyes. American Journal of Ophthalmology, 158, 215-220.e1. http://dx.doi.org/10.1016/j.ajo.2014.04.010

[27] Marques, E.F. and Ferreira, T.B. (2015) Comparison of Visual Outcomes of 2 Diffractive Trifocal Intraocular Lenses. Journal of Cataract \& Refractive Surgery, 41, 354-363. http://dx.doi.org/10.1016/j.jcrs.2014.05.048

[28] Esteve-Taboada, J.J., Domínguez-Vicent, A., Del Águila-Carrasco, A.J., Ferrer-Blasco, T. and Montés-Micó, R. (2015) Effect of Large Apertures on the Optical Quality of Three Multifocal Lenses. Journal of Refractive Surgery, 31, 666676. http://dx.doi.org/10.3928/1081597X-20150928-01 


\section{Submit or recommend next manuscript to SCIRP and we will provide best service for you:}

Accepting pre-submission inquiries through Email, Facebook, LinkedIn, Twitter, etc.

A wide selection of journals (inclusive of 9 subjects, more than 200 journals)

Providing 24-hour high-quality service

User-friendly online submission system

Fair and swift peer-review system

Efficient typesetting and proofreading procedure

Display of the result of downloads and visits, as well as the number of cited articles

Maximum dissemination of your research work

Submit your manuscript at: http://papersubmission.scirp.org/ 